In conclusion I would say that, while many cases of deformed nose are so extreme that nothing can be done for them in the way of operation, there are many others in which a distinct improvement may be brought about, which, though not always entirely satisfactory to the surgeon, is almost invariably appreciated by the grateful patient.

\section{ON THE VALUE OF LABORATORY RESEARCH} TO THE CLINICIAN.*

BY HKRBERT C. KMERSON, M.D., SPRINGFIKLD, MASS., Pathologist of the Springfield Hospital, Springfield, and of the Dickinson Hospital, Northampton, Mass.

I $\mathrm{T}$ is my purpose to call your attention to some of the methods of laboratory study of medical and surgical cases, and to emphasize the clinical advantages of general pathological work.

It is but a very few years ago that the busy general practitioner gave absolutely no attention to bacteriology, and almost none to pathological work. Save for an occasional examination of a tumor, physicians, as a rule, had no direct dealings with a pathologist. This is not to be wondered at, as laboratories were to be found only in connection with medical schools, the great hospitals themselves referring such pathological examinations as were important to the instructors in these schools.

Fifteen years ago, however, the discoveries in bacteriology gave an impetus to laboratory work which has steadily increased in power and scope and clinical usefulness. Continued examination and investigation led to new facts as to the cause and nature of morbid processes, and it soon became a necessity for the large hospitals to have thoroughly appointed laboratories as a part of their general equipment. Many of the smaller hospitals soon demauded the same outfit on a smaller scale, and so, within a few years, the general practitioner has been brought into very close touch with the work of hospital laboratories.

The one great end of all general practice of medicine, higher and broader than all others, is to relieve the suffering of humanity; and this is done, not in the laboratory, but by the physician, whenever aud whereever opportunity presents itself. But as a means to this eud, to enable the physician to make the correct diagnosis, to choose the successful remedy to relieve this suffering, the knowledge and assistance that laboratory investigation and research furnish is one of the dominant factors in successful scientific medicine to. day.

The most complete and painstaking clinical examination often fails to give us the definite information we ask, leaving questions like the following still in doubt:

Is this typhoid or malarial fever?

Has this patient a pelvic abscess, or chronic inflammation without pus?

Is this tonsilitis or diphtheria?

Answers to questions of this nature are in many cases determined by methods of study available only through laboratory investigation, which can be carried out only in pathological and bacteriological laboratories. This work really constitutes a distinct department of clinical pathology and bacteriology, and the catalogues of medical schools present courses of this character, both to graduates and undergraduates.

* Read at the meeting of the Hampden District Medical Society, Springfleld, Mass., April 19, 1898.
Permit me to quote one sentence from a recent address ${ }^{1}$ by one of the foremost clinicians of our day, Dr. F. C. Shattuck, of Boston. "The day is not far distant when every large hospital must have its pathological laboratory, as much as its operating room, with a trained and well-paid head, busied as much with the solution of problems arising in the living, as with the determination of the cause of death."

In presenting this subject to you in the way in which I am about to do, I make no pretense of complete and exhaustive treatment of the subjects as they are taken up, but I do aim to place before you some of the methods that are available to-day in our study of disease.

Blood. One of the most recent, as well as one of the most interesting side-lights of medical knowledge has been developed through the study and examination of the blood. ${ }^{2}$ Although an immense amount of work has been done along this line, it is only comparatively recently that such examinations have become common and essential to the diagnosis of various conditions. Not merely the estimation of the number of the red and white corpuscles, but the individual characteristics of these cells must be determined - their size, shape, staining capacity and structural composition.

The study of the numerous varieties of white bloodcorpuscles, or leucocytes, has given rise to many new diagnostic factors in many diseases, while our more exact knowledge of the different conditions that the red cells exhibit, is of great value, especially in the socalled blood diseases. Doubtful anemias and the degree of anemia are quickly determined by a study of the red cells; and the more or less severe secondary auemias at once differentiated from the primary or pernicious forms. Cases which present glandular swellings as the important feature should always be subjected to a complete blood examiuation, which will definitely settle the question of the presence of either variety of leukemia and Hodgkin's disease.

Aside from the help obtained from the blood in this class of diseases, the condition of the blood in many other diseases has been determined, and affords valuable data for making a differential diaguosis. This assistance is gained through the knowledge of the number of leucocytes present, an increase being constantly present in many diseases. 'This increase is called leucocytosis, and must consist of an increase in the adult form of white cells, or the polymorphonuclear variety. The normal number of leucocytes in adult blood is about 7,500 cells to the c. mm., and while they are increased in various physiological conditions, we are interested chiefly in the increase in pathological processes. For example: the white cells are largely increased in scarlet fever, and are usually normal in measles and German measles. They are increased in pneumonia, and normal in typhoid fever. Many cases of meningitis present the same symptoms as typhoid fever, but the presence of the leucocy tosis at once excludes the consideration of typhoid. Uncomplicated tuberculosis in all its forms presents an approximately normal count of the white cells, and if a meningitis is present its non-tubercular character would be at once diagnosticated by an examination of the blood.

This increase in the white cells is also always present in septic cases generally, and knowledge of this is of great practical benetit where deep-seated suppuration is going on, and the question is, Is pus present or not? Let me illustrate the value of this method of diagnosis 
by citing the following two cases which have lately been observed at the Springfield Hospital, in the service of Dr. R. H. Seelye :

Case I. P. H.. thirty-three years old; bar-tender; was operated on Decewber 18t, for appendicitis ; large abscess was found aud the wound drained. Bloodcount before operatiou showed 14,000 white cells. Patient did well, but ou December 6 th, 7 th and 8 th the temperature rose, aud patient complained of some pain. It was thought that there might be a pocket of pus below, and the advisability of opening up the wound was discussed. The blood-count, however, on each of these three days, showed a practically normal count of 8,000 white cefls, and no operation was done. Uuder the free use of saliues the temperature came down to normal, and convalescence has been uniuterrupted.

Case II. F. N., thirty-one years of age, housewife. Eutered the hospi al with the diagnosis of pus tubes, which the symptoms and physical signs seemed to bear out clearly. The blood showed but 6,000 white cells. At the operation no abscess or pus whatever was found, but large, thickened tubes and ovarian hematocele on either side.

Examination of the blood for micro-organisms gives positive results in some cases, and it is probable that this line of work will receive more attention in the future; but in all cases in which we suspect malarial infection, search should be made in the blood for Laveran's orgauism, the plasmodium malariæ, and if carefully sought after may be often demonstrated, and a doubtful diagnosis made positive. Thayer, ${ }^{8}$ whose brilliant and scientific study of malarial conditions renders his opinion invaluable, says: "The discovery of the parasites in the blood is the only diagnostic sign of malarial infectiou."

Typhoid Fever. The present laboratory methods of diaguosticating typhoid fever deserve a moment of special consideration. Ever since Eberth's ${ }^{4}$ discovery of this bacillus as the true causative agent of typhoid fever, its identification has been a matter of considerable difficulty, and never of practical application. The difficulty lies in the isolation of the organism, owing to the very close resemblance it and its cultures have to the cultures of the bacillus coli communis, which is universally found in the intestine. Several new methods ${ }^{5}$ for the cultivation of this organism and its differentiation from the colou bacillus have lately been tried, and with success, and it is now possible and practicable to make a diagnosis of this disease by isolating this specific organism from the feces, usually inside of forty-eight hours. Cultures may also be obtained from the uriue ${ }^{\circ}$ of the patient, and the bacilli may persist for a long period of time, - a fact of much practical importauce in convalescent cases. ${ }^{7}$

Another most valuable laboratory means of diagnosis of this disease consists in the Widal reaction, ${ }^{8}$ or serum test. The bacilli of typhoid fever are most actively motile organisms, and the serum reaction consists in the total arrest of their movements and their clumping together, when brought into direct contact with the blood or serum of a patient having typhoid fever, - the admixture being composed of one part of the serum, or watery solution of the blood, and 10 to 20 parts of the fresh culture of the bacilli in bouillon. This cessation of wovement and agglutination is generally complete in from fifteen to twenty minutes, but it may require an hour or even longer. The use of this test is es- pecially valuable in those doubtful cases of typhoid resembling grippe, meningitis, appendicitis, malarial fever and certain pulmonary affectious. This reaction cannot generally be seen till at least the fourth day of the disease, and the fact that it may be observed for a varying number of weeks after recovery has served to somewhat discredit its reliability as a diaguostic factor. But in a given case of suspected typhoid, a positive reaction is a most valuable diagnostic sign, and the fact that it is constantly present in typhoid and absent in other diseases adds great weight to its value.

In a recent article in the New York Medical Journal, 4,879 cases of typhoid taken from literature were reported, in which this reaction was tested, and positive results were obtained in 4,781 cases, or 97.9 per cent.

Diphtheria. In 1883 and 1884 the micro-organism knowv as the Klebs Löffler bacillus ${ }^{10}$ was demonstrated to be the infective agent in diphtheria, and the experience of the years since then has not served to throw doubt on the accuracy of this discovery. The bacilli are easily identified through their morphology and staining properties, when examined from a sixteen to twenty-four hours' growth on blood serum. 'The cultures are obtained by rubbing sterilized 8 wabs in the pharynx and then over the surface of the media.

It is generally recognized now that the diphtheritic bacilli may cause a very mild morbid process in the throat, as well as the extensive severe lesious. The nature of the disease in this last class is easily recognized, but it is absolutely impossible, in a large number of sore throats presented for treatment, to decide upon the character of the process, without a bacteriological examination. The pyogenic cocci, staphylo. cocci and streptococci may give rise to exactly similar local conditions as the bacilli of diphtheria, and cases doubtful in character should always receive the benefit of this decisive test. The greatest danger of infection from this disease comes through the unknown exposure to the mild, unrecognized cases of true diphtheria. While I never would put off using the antitoxiu in any urgent case I suspected to be diphtheria, until a bacteriological examination could be inade, I consider this means of diagnosis most valuable in indicating the use of antitoxin in many cases in which it would otherwise not be thought of.

It is in daily evidence that the bacilli remain in the throat for a varying length of time after all symptoms of diphtheria have disappeared, aud the throat is perfectly clean. Such cases should be considered, and are. sources of danger and further infection, as the bacilli persisting in the throat for three weeks after the disappearance of all symptoms ${ }^{11}$ have beeu proved to be as virulent as at the height of the disease; and until the throat of a patient that has had diphtheria is proved to be bacteriologically free from the bacilli, such a person should not be allowed to go and come in society, and be a source of concealed danger.

Sputum. The examination of the sputum of patients suspected to be tubercular has long been a routine practice with many men; but I wish to emphasize the importance of this procedure, particularly in cases in which the slightest suspicion is aroused, and as early in the case as possible.

A young man of fairly good health came to me last summer, with the history of coughing up a very small quantity of blood on the day before, and again on the morning of this visit. He brought the specimen to show me, but said be did not think much about it, as 
he had always had catarrh. The specimen consisted of 20 c. c. of bright frothy blood, in which I found fairly numerous tubercle bacilli. The pbysical signs were almost nothing, and yet the establishment of the diagnosis at this early stage of the process was most opportune for the patient.

The very early diagnosis of tuberculosis means an immense increase in the chances for arrest of the process and healing of the wound, and the sputum should be examined as early as it is possible to secure it.

The bacteriological examination of all fluids and exudatious in the body, occurring in all sorts of pathological conditions, gives us new insight into the etiology of morbid processes, and often affords us help when it is least expected.

The detection of the gonococcus, if present, in the discharge from a doubtful urethritis, in many cases of raginal discharge, in purulent conjunctivitis in infants and adults as well, is of the greatest importance to the physician and patient, and may further serve to suggest the preferable treatment. ${ }^{12}$ The bacillus of diphtheria does not confine its visitations to the throat and nose, but may also be found in pus from the eye, ear and vagina.

Examination of the urine and feces will frequently give results of positive value for diagnosis in cases otherwise obscure - tubercle bacilli, for instance, may be often demonstrated in these excretions in doubtful intestinal and genito-urinary disorders.

In cases of meningitis it is now considered practicable for purposes of diagnosis to withdraw some of the cerebro-spinal tluid by lumbar puncture. ${ }^{18}$ In this fluid tubercle bacilli may be demonstrated, or in the opidemic cerebro-spinal variety the specific organism, a diplococcus, may be easily found.

Microscopical examinations of new growths constitute a large part of a pathologist's work, and yet in this field alone there is room for a great deal more study and investigation of value to both patient and surgeon. Routine examiuation of all tumors, large aud small, is a practice not at all common, except possibly in the medical centres; yet without such routine practice most valuable information of early malignancy must occasionally escape the surgeon's notice. I have in mind two cases of aural polypi, in which nothing unusual was suspected at time of operation, yet the malignancy of the one and the tubercular character of the other established at once the real cause of 85 mptoms that shortly appeared.

\section{AUTHORITIES REFERRED TO.}

1. Shattuck. Boston Medical and Surgical Journal, June 24, $18 ! 17$.

2. Cabot. Clinical Ex ،mination of the Blood, 1897.

3. Thayer. Yale Medical Journal, January, 1898.

4. Günther. Bacteriologie, 1895 . 5. Hiss. The Journal of Experimental Medicine, November,

6. Richardson. Boston Medical and Surgical Journal, October

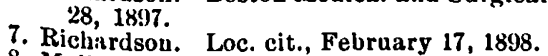

8. Mallory and Wright., Pathological 'Techuique, 1897.

9. Brille. New York Medical Journal, Jauuary $8,1898$.

10. Günther. Bacteriologie, 1895.

11. Stone. Boston Journal for Medical Sciences, vol. ii, No. 2, 1897.

12. Standish. Boston Medical and Surgical Journal, August 5, 1897.

13. Williams. Medical and Surgical Reports of Boston City Hospital, 1898.

A Departant for the treatment of hydrophobia by Pasteur's method has been opened at the Berlin Institute for Infectious Diseases.

\section{Alinical \&Department.}

LOCAL MUSCULAR WEAKNESS AS A CAUSE OF JOIN'T IRRITATIUN. ${ }^{1}$

BY ROBERT W. LOVET', M.D., BOSTON.

IN formulating what must be common experience to you all, I am anxious to insist upon a factor which has not yet found its way into literature to any extent, and which seems to me to play an important part in joint affections, especially in the late history of joint injuries and inflammations.

Joiuts must depend for their proper mechanical use not only upon the well-being of cartilage, synovial membrane, and ligaments, but also upon the tone and strength of the muscles controlling them. Strong muscles protect joints and render them less vulnerable, weak muscles deprive the joints of their normal support, increase the liability to injury and throw an un. due proportion of work upon the ligaments and joint structures. I beg your consideration of some cases illustrating these points:

Case 1. A case of synovitis apparently due to muscular weakness. A healthy young girl, sixteen years old, was referred to me in November, 1897, by Dr. W. L. Richardson. Six years ago she had wrenched her right knee while crossing the oceau aud the kuee was sore after it for a long time. She could walk upon it and was never confined to bed. It got better, although it did not entirely recover, and a year later she wrenched it again. 'Three years ago sbe sprained it so badly that she was in bed with it; slight sprains have been occurring ever since and have become more frequent during the last year. 'Two years ago she sprained the other knee aud has had some slight sprains on that side which have also increased in frequency, but the right knee continued the worst and was more frequently injured. For the last few months pain has been present in both knees most of the time, but this pain has never been severe enough to suggest a dislocation of the patella or of the semilunar cartilages. It was aggravated by standing or walking and the patient was unable to walk one-half mile without severe pain. There is no rheumatisn in the family and no personal history of any.

The girl was well developed, tall but slender; she walked with an unsteady swaying gait evidently due to imperfect flexion of the knees. There was no flatfoot or marked prouation of the foot, motion was perfect and there was no grating, the patellar reflexes were normal and there were no symptoms of any organic nervous disease. On examination the smull size of the thighs was the striking feature, the calves were better by comparison, but were poorly developed. There was a moderate effusion in the right kueejoint with some thickening of the synovial membrane and a little tenderuess. There was a slight effusion in the left kuee-joint. It was obviously for these reasons not a purely hysterical affectiou, and I made the diagnosis of double synovitis due to constant traumatisms of the joints on account of imperfect muscular support. As the knee-joints when seen were obviously in a condition of subacute inflammation, it seemed to me that fixation was tirst needed to cure this irritation ; the treatment therefore consisted of fixation by a ham-splint, with compression to the right knee1 Read by title before the American Orthopedic Association, Bos-
ton, May 17, 1898 . 